Eur. J. Clin. Chem. Clin. Biochem.

Vol. 32, 1994, pp. 827-831

(c) 1994 Walter de Gruyter \& Co. Berlin - New York

\title{
Accelerated Bone Degradation in Thyroid Carcinoma Patients during Thyroxine Treatment, Measured by Determination of the Carboxyterminal Telopeptide Region of Type I Collagen in Serum ${ }^{1}$ )
}

\author{
By Eeva Taimela ${ }^{1}$, Simo Taimela ${ }^{2}$, Väinämö Nikkanen ${ }^{3}$ and Kerttu Irjala ${ }^{1}$ \\ 1 Department of Clinical Chemistry, Central Laboratory, University Central Hospital of Turku, Turku, Finland \\ 2 Helsinki Research Institute for Sports and Exercise Medicine, Helsinki, Finland \\ ${ }^{3}$ Department of Radiotherapy and Oncology, University Central Hospital of Turku, Turku, Finland
}

(Received May 2/September 10, 1994)

Summary: We studied the effects of long-term suppressive thyroxine treatment on serum markers of bone collagen synthesis and degradation in thyroid carcinoma patients, and the relationship of these effects to the serum concentrations of thyrotropin, free thyroxine and free triiodothyronine were investigated.

Thirty-seven thyroid carcinoma patients receiving a stable thyroxine dose, and thirty-five controls participated in a cross-sectional study. Bone collagen synthesis and degradation were measured by using specific radioimmunoassays to determine the serum concentrations of carboxyterminal propeptide of type I procollagen, and carboxyterminal telopeptide region of type I collagen, respectively. Serum thyrotropin, free $T_{4}$ and free $T_{3}$ were measured by timeresolved fluoroimmunoassays (Delfia ${ }^{\circledR}$ ). Serum carboxyterminal telopeptide region of type I collagen concentrations of thyroid carcinoma patients were significantly higher than those of the controls $(p=0.0012)$. Serum carboxyterminal propeptide of type I procollagen concentrations did not differ significantly between the patients and controls $(p=0.85)$. Significant associations between age or physical activity, and carboxyterminal propeptide of type I procollagen or carboxyterminal telopeptide region of type I collagen were found in the controls, but not in the patients. Thyrotropin, free $T_{4}$ or free $T_{3}$ were not significantly associated with carboxyterminal propeptide of type I procollagen or carboxyterminal telopeptide region of type I collagen in either the control or patient group.

From these results it is concluded that long-term suppressive thyroxine treatment seems to accelerate bone degradation, but not bone formation, and therefore carries a risk for osteoporosis. Thyrotropin or free thyroid hormones were not able to predict the accelerated bone degradation within the patient group. The normal regulation of bone metabolism is altèred during long-term high dose thyroxine treatment, as evidenced by the fact that the effects of age and physical activity were not seen in patients. Differentiated thyroid cancer is generally diagnosed in young people, and patients may receive high-dose thyroxine treatment for decades. Problems due to side effects, like accelerated bone degradation, may arise gradually. This risk should be taken into account in the management of thyroid carcinoma patients.

\section{Introduction}

Patients with thyroid carcinoma need postoperative thyroxine substitution. The optimal degree of thyrotropin

1) Carboxyterminal propeptide of type I procollagen and carboxyterminal telopeptide region of type I collagen assays were kindly donated from Orion Diagnostica, Turku, Finland. suppression, however, remains uncertain (1). Long-term suppressive thyroxine treatment may cause side effects such as an increased risk of osteoporosis $(2,3)$. Conventional methods for studying bone metabolism and osteoporosis include measurements of bone mineral density. These methods are expensive, sometimes laborious, and utilize radiation. Biochemical markers for bone metabolism have also been used, such as urinary hydroxypro- 
line, pyridinoline and deoxypyridinoline cross-links. However, if urinary hydroxyproline is used as an index, the subject must receive a special diet. New techniques have been developed for the measurement of specific indicators of bone metabolism in a single serum sample. Type I collagen accounts for 90 percent of the organic matrix of bone. Carboxyterminal propeptide of type I procollagen is an indicator of type I collagen synthesis in the body, and carboxyterminal telopeptide parts of type I collagen are a corresponding indicator of the degradation of type I collagen. These new serum markers have made it possible to measure bone metabolism easily $(4,5)$.

The aims of the present study were to examine:

1) whether long-term thyroxine treatment for the suppression of thyrotropin secretion has effects on biochemical markers of bone metabolism in thyroid cancer patients;

2) the value of thyrotropin, free thyroxine, and free triiodothyronine in the prediction of the possible alterations in bone metabolism.

\section{Materials and Methods}

\section{Subjects}

Thirty-seven patients who had undergone a primary radical operation for differentiated papillary or follicular thyroid carcinoma, and thirty-five controls participated in the study. All patients received long-term suppressive thyroxine treatment. Subject characteristics are presented in table 1 . The procedures followed were in accordance with the Helsinki Declaration of 1975, as revised in 1983.

\section{Laboratory methods}

Bone collagen synthesis and degradation were determined by measuring the serum concentrations of carboxyterminal propeptide of type I procollagen, and carboxyterminal telopeptide region of type I collagen, respectively (Orion Diagnostica, Finland), using specific radioimmunoassays $(4,6)$. Carboxyterminal propeptide of type I procollagen is a trimeric, globular protein that is cleaved off from type I collagen molecules beforte the latter are assembled into fibers. This cleavage must be complete to ensure correct fibril and fiber formation. Thus the amount of carboxyterminal propeptide of type I procollagen released is directly related to the number of collagen molecules formed, and the assay of carboxyterminal propeptide of type I procollagen can be used to quantify type I collagen synthesis in the body. Carboxyterminal telopeptide region of type I collagen is a cross-linked telopeptide from type I collagen fibres. It is liberated during the degradation of type I collagen, and the carboxyterminal telopeptide region of type I collagen assay can be used to quantify type I collagen degradation in the body. Serum thyrotropin was measured with a third-generation assay based on time-resolved fluorescence (Delfia ${ }^{\circledR}$ hTSH Ultra, Wallac, Finland) with a reference interval of $0.5-4.7 \mathrm{mIU} / \mathrm{l}$ established by our own laboratory. The functional sensitivity of the thyrotropin method was $0.005 \mathrm{mIU} / \mathrm{l}\left(20 \%\right.$ between-assay CV) $(7)$. Serum free $\mathrm{T}_{4}$ and free $\mathrm{T}_{3}$ were also measured with time-resolved fluoroimmunoassays (Delfia). Reference intervals for free $T_{4}$ and free $T_{3}$ were 7.6-19.7 $\mathrm{pmol} / \mathrm{l}$ (according to manufacturer) and 4.2-7.6 pmol/1 (established by our own laboratory).

\section{Physical activity index}

Participation in leisure-time physical activity was assessed by using a questionnaire. The subjects were asked the frequency of participation in physical activity and the average intensity and duration of exercise. A sum index for physical activity was calculated from the product of intensity $\times$ duration $x$ monthly frequency $(8,9)$.

\section{Statistics}

Serum carboxyterminal telopeptide region of type I collagen values were long transformed for parametric statistical computations, because the distribution was skewed. The results of thyrotropin, free

Tab. 1 Subject characteristics. The values are presented as mean (SD). Hormone concentrations are presented as median (range).

\begin{tabular}{|c|c|c|c|c|c|c|c|}
\hline & $\begin{array}{l}\text { Age } \\
\text { (years) }\end{array}$ & $\begin{array}{l}\text { Duration of } \\
\text { thyroxine } \\
\text { treatment } \\
\text { (months) }\end{array}$ & $\begin{array}{l}\text { Thyroxine } \\
\text { dosage } \\
(\mu \mathrm{g} / \mathrm{d})\end{array}$ & $\begin{array}{l}\text { Physical } \\
\text { activity } \\
\text { index }\end{array}$ & $\begin{array}{l}\text { Thyrotropin } \\
\text { (mIU/l) }\end{array}$ & $\begin{array}{l}\text { Free } T_{4} \\
(p m o l / l)\end{array}$ & $\begin{array}{l}\text { Free } T_{3} \\
(\mathrm{pmol} / \mathrm{l})\end{array}$ \\
\hline \multicolumn{8}{|l|}{ Males } \\
\hline $\begin{array}{l}\text { Controls } \\
\qquad(\mathrm{n}=7)\end{array}$ & $48.8(8.0)$ & - & - & $55.4(57)$ & $1.4 \quad\left(\begin{array}{ll}0.8 & -2.2\end{array}\right)$ & $13.2(11.6-18.2)$ & $5.6(4.7-7.7)$ \\
\hline $\begin{array}{l}\text { Patients } \\
\quad(n=9)\end{array}$ & $55.8(9.2)$ & $48.2(31)$ & $197(48)$ & $39.6(29)$ & $0.019(<0.005-0.7)$ & $20.9(14.7-25.6)$ & $4.6(3.1-.7 .7)$ \\
\hline \multicolumn{8}{|c|}{ Females (premenopausal) } \\
\hline $\begin{array}{l}\text { Controls } \\
(n=23)\end{array}$ & $38.3(8.5)$ & - & - & $45.3(35)$ & $\left.\begin{array}{lll}1.8 & (0.7 & -6.8\end{array}\right)$ & $13.6(10.0-16.4)$ & $5.6(3.9-7.4)$ \\
\hline $\begin{array}{l}\text { Patients } \\
\qquad(\mathrm{n}=19)\end{array}$ & $35.5(9.8)$ & $39.6(15)$ & $227(41)$ & $52.0(34)$ & $0.013(<0.005-0.7)$ & $26.8(15.4-45.7)$ & $6.4(3.6-13.3)$ \\
\hline \multicolumn{8}{|c|}{ Females (postmenopausal) } \\
\hline $\begin{array}{l}\text { Controls } \\
\quad(n=5)\end{array}$ & $51.4(6.4)$ & - & - & $50.7(34)$ & $\left(\begin{array}{ll}1.3 & -3.1\end{array}\right)$ & $13.8(11.9-14.5)$ & $5.1(4.8-6.6)$ \\
\hline $\begin{array}{l}\text { Patients } \\
\quad(n=9)\end{array}$ & $52.7(3.4)$ & $56.4(51)$ & $203(32)$ & $45.4(40)$ & $0.009(<0.005-0.06)$ & $\begin{array}{c}23.5(16.8-30.0) \\
.\end{array}$ & $5.9(3.4-7.6)$ \\
\hline
\end{tabular}


$T_{4}$ and free $T_{3}$ are presented as medians, and non-parametric analyses (Mann-Whitney U-test) were used in the statistical computations, bccause the distribution was highly skewed. According to sex and menopausal status, the subjects were classified into males, premenopausal females, and postmenopausal females. Carboxyterminal telopeptide region of type I collagen and carboxyterminal propeptide of type I procollagen were examined between patients and controls (group) using an analysis of variance (group, menopausal status) and covariance (age, physical activity index). No significant group by menopause interaction was found.

The relations of carboxyterminal telopeptide region of type I collagen and carboxyterminal propeptide of type I procollagen to thyrotropin, free $T_{4}$, free $T_{3}$, age and physical activity were examined using linear regression analyses stratified by patient and control groups. Analyses were performed using version 6.04 of the Statistical Analysis System (SAS) scientific software for microcomputers, and confidence intervals were calculated using the CIA (Confidence Interval Analysis) software (10).

\section{Results}

Table 2 shows serum carboxyterminal propeptide of type I procollagen and carboxyterminal telopeptide region of type I collagen concentrations in the controls and patients. Mean serum carboxyterminal telopeptide region of type I collagen concentrations in thyroid carcinoma patients were higher than in controls $(p=0.0012)$. Mean serum carboxyterminal propeptide of type I procollagen concentrations did not differ significantly between patients and controls $(p=0.85)$. No significant differences were found between genders and menopausal groups. Age and physical activity were included as covariates in the analyses.

In the control group, linear regression analyses revealed that age and physical activity were significantly related to bone formation (carboxyterminal propeptide of type I procollagen $=0.29 \times$ physical activity index $-0.82 \times$

Tab. 2 Serum concentrations of carboxyterminal propeptide of type I procollagen (PICP), and carboxyterminal telopeptide region of type I collagen (ICTP) in controls and patients. The values are presented as means, and $95 \%$ confidence intervals are shown in parentheses. Mean serum carboxyterminal telopeptide region of type I collagen concentrations in thyroid carcinoma patients were higher than in controls $(p=0.0012)$, when an analysis of variance (group, menopausal status) and covariance (age, physical activity index) was used. Means shown in the table are non-adjusted.

\begin{tabular}{|c|c|c|}
\hline & PICP $(\mu \mathrm{g} / 1)$ & ICTP $(\mu \mathrm{g} / 1)$ \\
\hline \multicolumn{3}{|l|}{ Males } \\
\hline $\begin{array}{l}\text { Controls }(n=7) \\
\text { Patients }(n=9)\end{array}$ & $\begin{array}{l}114.2(97.1 \text { to } 131) \\
104.9(80.4 \text { to } 129)\end{array}$ & $\begin{array}{l}2.5(1.8 \text { to } 3.2) \\
3.1(2.6 \text { to } 3.6)\end{array}$ \\
\hline \multicolumn{3}{|c|}{ Fẹmales (premenopausal) } \\
\hline $\begin{array}{l}\text { Controls }(n=23) \\
\text { Patients }(n=19)\end{array}$ & $\begin{array}{l}109.4(101.0 \text { to } 118) \\
104.2(89.2 \text { to } 119)\end{array}$ & $\begin{array}{l}2.8(2.4 \text { to } 3.2) \\
3.6(2.9 \text { to } 4.3)\end{array}$ \\
\hline \multicolumn{3}{|c|}{ Females (postmenopausal) } \\
\hline $\begin{array}{l}\text { Controls }(n=5) \\
\text { Patients }(n=9)\end{array}$ & $\begin{array}{l}101.0(82.6 \text { to } 119) \\
103.9(83.2 \text { to } 125)\end{array}$ & $\begin{array}{l}2.6(1.4 \text { to } 3.8) \\
4.0(3.2 \text { to } 4.8)\end{array}$ \\
\hline
\end{tabular}

age $+92.96 ; R^{2}=41 \%$ ). Also, age was significantly .related to bone degradation (log carboxyterminal telopeptide region of type I collagen $=1.73-0.014 \times$ age; $\mathrm{R}^{2}=31 \%$ ) in the controls. In contrast, no significant associations between age or physical activity, and carboxyterminal propeptide of type I procollagen or carboxyterminal telopeptide region of type I collagen were found in the patients. Figure 1 shows the effect of age on serum markers of bone formation and degradation in the patients and the controls. Thyrotropin, free $T_{4}$ or free $\mathrm{T}_{3}$ were not significantly associated with carboxyterminal propeptide of type I procollagen or carboxyterminal telopeptide region of type I collagen within either the control or patient group in the linear regression analyses.

\section{Discussion}

The present study confirmed the finding that the ratio of bone resorption to bone formation is altered in states with high thyroid hormone concentrations. Many studies have shown that thyrotropin suppression caused by high doses of thyroid hormones decreases bone mass (1114). Recently, it was also shown that thyroxine treatment with lower doses, in order to keep thyrotropin in reference interval, has only minor effect, if any, on bone mass $(15,16)$. In these studies, bone mass and metabolism were studied by measurement of bone mineral density and biochemical markers of bone formation and resorption, such as serum alkaline phosphatase, osteocalcin, urinary hydroxyproline, and urinary pyridinium crosslinks. The advantage of the new serum bone markers used in the present study, carboxyterminal propeptide of type I procollagen and carboxyterminal telopeptide region of type I collagen, lies in their high specificity for type I collagen which represents $90 \%$ of the organic bone matrix. These radioimmunoassays are easy to perform, and both measurements correlate well with bone mass according to histomorphometric studies (17). Bone mineral density or content cannot be defined by any biochemical marker. However, carboxyterminal propeptide of type I procollagen and carboxyterminal telopeptide region of type I collagen can be used as indicators of bone turnover. Factors affecting the elimination of carboxyterminal propeptide of type I procollagen and carboxyterminal telopeptide region of type I collagen, e.g. increased glomerular filtration, were not studied in the present work.

In the present study, age and physical activity were significantly related to a serum marker of bone formation, and age to a serum marker of bone degradation in the controls. This is in agreement with previous studies (1S). No such associations were found in the patients. It seems that bone degradation is accelerated during long-term 


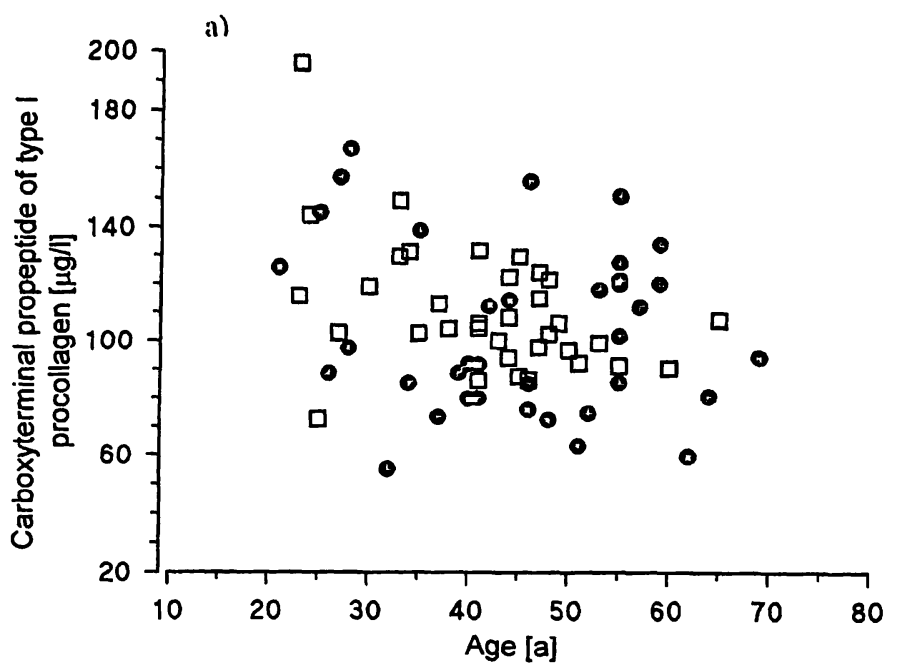

Fig. 1 The effect of age on serum concentrations of carboxyterminal propeptide of type I procollagen (1a), and carboxyterminal

high dose thyroxine therapy. The normal regulation of bone metabolism is altered during long-term high dose thyroxine treatment, since the effects of age and physical activity were not seen in patients. As patients received thyroid hormone treatment, obvious differences were found in thyrotropin and thyroid hormone status between the patients and controls. Although bone degradation seems to be accelerated in the patient group (free thyroid hormone concentrations were higher and thyrotropin concentrations were lower than in the controls), these hormone concentrations were not able to predict the level of the serum marker of bone degradation within the patient group in the present study. The age differences between the male patients and controls had no major effect on the results of the present study, as age was included as a covariate in the statistical analyses.

\section{References}

1. Mazzaferri, E. L. (1993) Management of a solitary thyroid nodule. N. Engl. J. Med. 328, 553-559.

2. Harvey, R. D., McHardy, K. C., Reid, I. W., Paterson, F., Bewsher, P. D., Duncan, A. \& Robins, S. P. (1991) Measurement of bone collagen degradation in hyperthyroidism and during thyroxine replacement therapy using pyridinium crosslinks as specific urinary markers. J. Clin. Endocrinol. Metab. $72,1189-1194$.

3. Paul, T. L., Kerrgian, J., Kelly, A. M., Braverman, L. E. \& Baran, D. T. (1988) Long-term L-thyroxine therapy is associated with decreased hip bone density in premenopausal women. J. Am. Med. Ass. 259, 3137-3141.

4. Melkko, J., Niemi, S., Risteli, L. \& Risteli, J. (1990) Radioimmunoassay of the carboxyterminal propeptide of human type I procollagen. Clin. Chem. 36, 1328-1332.

5. Risteli, J., Elomaa, I., Niemi, S., Novamo, A. \& Risteli, L. (1993) Radioimmunoassay for the pyridinoline cross-linked carboxy-terminal telopeptide of type I collagen: A new serum marker of bone collagen degradation. Clin. Chem. 39, 635640 .

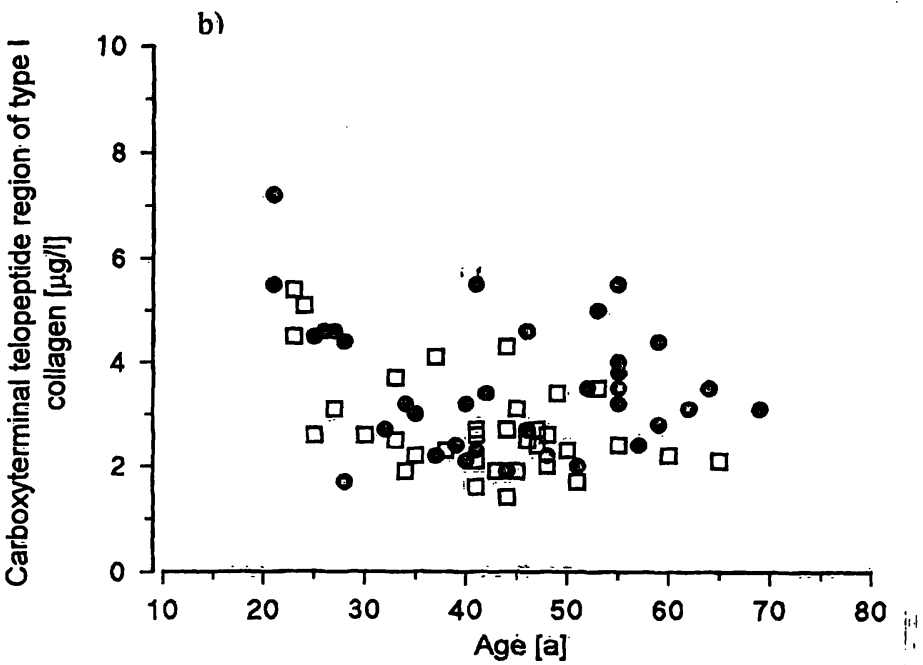

telopeptide region of type I collagen (lb) in controls ( $\square$ ) and patients (Q).

In conclusion, long-term suppressive thyroxine treatment increases a serum marker of bone degradation in men, and in premenopausal and postmenopausal women. Differentiated thyroid cancer is generally diagnosed in young people and the patients may receive high-dose thyroxine treatment for decades. Problems due to side effects, such as accelerated bone degradation, may arise gradually. Serum thyrotropin or free thyroid hormone concentrations were not reliable indicators of the level of the serum marker of bone degradation within the patient group. Thyroid hormones and thyrotropin suppression are essential for thyroid carcinoma patients. Therefore, longitudinal studies are needed in order to define the optimal amount of thyroxine and the degree of thyrotropin suppression, taking into account the side effects of the treatment.

6. Risteli, J., Melkko, J., Niemi, S. \& Risteli, L. (1991) Use of a marker of collagen formation in osteoporosis studies. Calcif. Tissue Int. 49, 24-25.

7. Taimela, E., Koskinen, P. \& Irjala, K. (1994) Time-resolved immunofluorometric assay for thyrotropin improved for enhanced functional sensitivity and clinical discrimination. Scand. J. Clin. Lab. Invest. 54, 317-321.

8. Anon. (1990) American college of sports medicine position stand. The recommended quantity and quality of exercise for developing and maintaining cardiorespiratory and muscular fitness in healthy adults. Med. Sci. Sports Exerc. 22, 265-274.

9. Wilson, P. W. F., Paffenbarger, R. S., Morris, J. N. \& Havlik, R. J. (1986) Assessment methods for physical activity and +1 physical fitness in population studies; Report of a NHLBI workshop. Am. Heart. J. 111, 1177, 1192 .

10. Gardner, M. J. \& Altman, D. G., eds. (1989) Statistics with Confidence. British Medical Journal, London.

11. Ross, D. S., Neer, R. M., Ridgway, E. C. \& Daniels, G. H." (1987) Subclinical hyperthyroidism and reduced bone density as a possible result of prolonged suppression of the pituitarythyroid axis with L-thyroxing. Am. J. Med. 82, 1167-1170. 
12. Diamond, T., Nery, L. \& Hales, I. (1990) A therapeutic dilemma: Suppressive doses of thyroxine significantly reduce bone mineral measurements in both premenopausal and postmenopausal women with thyroid carcinoma. J. Clin. Endocrinol. Metab. 72, 1184-1188.

13. Wakasugi, M., Wakao, R., Tawata, M., Gan, N., Koizumi, K. \& Onaya, T. (1993) Bone mineral density in patients with hyperthyroidism measured by dual energy X-ray absorptiometry. Clin. Endocrinol. 38, 283-286.

14. Adlin, E. V., Maurer, A. H., Marks, A. D. \& Channick, B. J. (1991) Bone mineral density in postmenopausal women treated with L-thyroxine. Am. J. Med. 90, 360-366.

15. Greenspan, S. L., Greenspan, F. S., Resnick, N. M., Block, J. E., Friedlander, A. L. \& Genant, H. K. (1991) Skeletal integrity in premenopausal and postmenopausal women receiving longterm L-thyroxine therapy. Am. J. Med. 91, 5-14.
16. Franklyn, J. A., Betteridge, J., Daykin, J., Holder, R., Oates, G. D., Parle, J. V., Lilley, J., Heath, D. A. \& Sheppard, M. C. (1992) Long-term thyroxine treatment and bone mineral density'. Lancet 340, 9-13.

17. Eriksen, E. F., Charles, P., Melsen, F., Mosekilde, L., Risteli, L. \& Risteli, J. (1993) Serum markers of type I collagen formation and degradation in metabolic bone disease: Correlation to bone histomorphometry. J. Bone Miner. Res. 8, 127-132.

18. Suominen, H. (1993) Bone mineral density and long term exercise. Sports Medicine 16, 316-330.

Eeva Taimela, M.D.

Department of Clinical Chemistry

University Central Hospital of Turku

Kiinamyllynkatu 4-8

FIN-20520 Turku

Finland 
